\title{
PELVIURETERIC JUNCTION (P.U.J.) OBSTRUCTION, ITS EVALUATION BY SONOGRAPHY (USG), USING PELVIS / CORTEX RATIO.
}

\section{Dr. Rahul Goel}

\author{
Department of Surgery , Muzaffarnagar Medical College , Muzaffarnagar.
}

ABSTRACT Objectives- Aim of this study was to document pelvis/cortex ratio, (P/C ratio) in children presenting with obstruction.

Material and Methods- All children presenting with unilateral hydronephrosis (PUJ) between January 2009-March 2015 were included. Ultrasound was performed by the same radiologist and $\mathrm{P} / \mathrm{C}$ ratio was determined by dividing maximum anteroposterior pelvic diameter with maximum cortical thickness.

Results- Among a total of 111 children 87 (78\%) improved on conservative management, while $24(22 \%)$ required surgery (pyeloplasty). The mean (+-SD) P/C ratio was $2.7+-2.18$ in those improved on conservative management, while $13.5+-1.48$ in those who required surgery $(\mathrm{p}<0.01)$. All $(22 / 22)$ children with $\mathrm{P} / \mathrm{C}$ ratio of 12 or above required pyeloplasty, while $2 / 5$ with $\mathrm{P} / \mathrm{C}$ ratio 8-12 and none (0/84) with $\mathrm{P} / \mathrm{C}$ ratio less than 8 required pyeloplasty $(\mathrm{p}<0.01)$

Conclusion- $\mathrm{P} / \mathrm{C}$ ratio could be used as a marker of PU obstruction in children with hydronephrosis.

\section{KEYWORDS :}

\section{INTRODUCTION-}

PUJ obstruction is common antenatal ultrasound finding (1), USG and Radionuclide Renogram $(2,3)$ are widely used to identify those requiring pyeloplasty, though renogram is the gold standard. The sonographic criteria for pyeloplasty is not defined in literature(4-5), the A-P diameter (anteroposterior) APPD, is widely used to describe severity of hydronephrosis on ultrasound, though its efficacy is debated for surgical purpose (6-9). Renal parenchymal to pelvicalyceal area has been used successfully to predict the need for pyeloplasty (10-12), our study shows (P/C ratio ) was superior to APPD as a marker of success following pyeloplasty in children(13). In this study we analyse the role of $\mathrm{P} / \mathrm{C}$ in the follow up of children with antenatally diagnosed hydronephrosis and addressed its usefulness in selection of patients who require surgery.

\section{MATERIAL AND METHODS-}

All children of unilateral foetal hydronephrosis between Jan 2009- March 2015 were included. B/L Hydronephrosis , VUR and associated anomalies were excluded, all patients were followed with USG and Renogram at 3 months intervals, and decision for pyeloplasty was a drop of more than $10 \%$ split function on Renogram.

During entire follow up USG was done by same radiologist and same machine to avoid bias, the maximum APPD (anteroposterior pelvic diameter) was measured in coronal section and maximum Polar Cortical thickness (CT), was measured in longitudinal section accurately. $\mathrm{P} / \mathrm{C}$ ratio was calculated by dividing maximum APPD with maximum CT.

Mean P/C ratio was compared between those who improved on conservative treatment and those who required surgery (pyeloplasty). Further analysis of $\mathrm{P} / \mathrm{C}$ ratio versus outcome was performed, and was expressed in percentage. Statistical analysis was done using students $t$ test and Fishers exact test and the difference in outcome was considered significant when the Pvalue was less than 0.05 .

\section{RESULTS}

Total of 111 children (age range 1 month to 5 years: $\mathrm{M}-\mathrm{F}=2: 1$; median follow up $=25$ months), 87 (78\%) improved conservatively, while $24(22 \%)$ required pyeloplasty. The mean (+-SD) $\mathrm{P} / \mathrm{C}$ ratio was $2.7+-2.18$ in those with medical treatment, and $13.5+-1.48$ in those requiring surgery ( pyeloplasty). The difference between the groups was statistically significant $(\mathrm{P}<0.01$ students t test $)$
Table 1 : Table showing the outcome based on $\mathrm{P} / \mathrm{C}$ ratio. All children with $\mathrm{P} / \mathrm{C}$ ratio of 12 or above required pyeloplasty while only $2 / 5$ with $\mathrm{P} / \mathrm{C}$ ratio $8-12$, and none of those with $\mathrm{P} / \mathrm{C}$ ratio $<8$ required pyeloplasty ( $\mathrm{P}<0.01$ Fisher's exact test )

\begin{tabular}{|c|c|c|c|}
\hline P/C ratio & Pyeloplasty & Conservative & Total \\
\hline$>12$ & 22 & 0 & 22 \\
\hline $8-12$ & 2 & 3 & 5 \\
\hline$<8$ & 0 & 84 & 84 \\
\hline Total & 24 & 87 & 111 \\
\hline
\end{tabular}

\section{DISCUSSION-}

Antenatal hydronephrosis is $1-5 \%$, PUJ obstruction and physiological pelvic dilatation are important cause of unilateral hydronephrosis(1). Renogram is gold standard in evaluation and loss of function in progressive renal scans is the criterion to determine the presence of obstruction.

Hafez et al (4) felt pattern on serial USG were superior to invasive renography. Dhillon (5) recommended simple follow up for pelvic dilatations less than $12 \mathrm{~mm}$, while surgery for those more than $50 \mathrm{~mm}$. For the $20-50 \mathrm{~mm}$ surgery recommended in patients with reduced function, increased symptoms and dilatation. Cost et al (11) felt renal parenchyma thickness to provide accurate estimate of renal function in the hydronephrotic kidney.

In the present study, we have analysed the role of $\mathrm{P} / \mathrm{C}$ ratio in the evaluation of children who presented with antenatally diagnosed hydronephrosis . All patients with $\mathrm{P} / \mathrm{C}$ ratio above 12 required pyeloplasty, and children with $\mathrm{P} / \mathrm{C}$ ratio less than 8 were managed without surgery. In the group with $\mathrm{P} / \mathrm{C}$ ratio 8 $12,2 / 5(40 \%)$ required pyeloplasty.

Standardization of USG is an essential step in making it a useful tool. $\mathrm{P} / \mathrm{C}$ ratio could be useful, non invasive and simple criterion in addition to diuretic renogram parameters in selection of patients with significant obstruction and requiring pyeloplasty. Further large studies would be needed to strengthen or negate the evidence.

\section{REFERENCES}

1. Babu R, Sai V Postnatal outcome of foetal hydronephrosis: Implications for prenatal counselling. IJU 2010;26:59-61

2. Conway JJ. MaizelsM. The well tempered diuretic renogram: a standard method to examine the asymptomatic neonate with hydronephrosis or hydroureteronephrosis. A report from combined meetings of the society for Fetal Urology and members of the paediatric Nuclear Medicine Council- The society of Nuclear Medicine.JNucl Med1992;33:2047-51

3. Stocks A, Richard D, Frentzen B, Richard G. Correlation of prenatal renal pelvic anteroposterior diameter with outcome in infancy .JUrol 1996;155:1050-2

4. Hafez AT, Mclorie G, Bagli D, Khoury A. Analysis of trends on serial ultrasound for high grade neonatal hydronephrosis .J Urol 2002;168:1518-21 
5. Dhillon HK. Prenatally diagnosed hydronephrosis :the great Ormond street experience. Br Jurol 1998;81:39-44

6. Onen A. Treatment and outcome of prenatally detected newborn hydronephrosis .J Pediatr Urol 2007;3:469-76

7. Onen A Jayanthi VR ,Koff SA .Long term follow up of prenatally detected severe bilateral newborn hydronephrosis initially managed nonoperatively J Urol 2002; 168:1118-20

8. Onen A. An alternative grading system to refine the criteria for severity of hydronephrosis and optimal treatment guidelines in neonates with primary UPJ -type hydronephrosis. J Pediatr Urol 2007;3;200-5

9. Palmer LS, Maizels M, Cartwright PC, Fernbach SK,Conway JJ. Surgery vs observation for managing obstructive grade 3 to 4 unilateral hydronephrosis: a report from the society for Fetal Urology .J Urol 1998:159:222-8

10. Rodriguez LV, Lock J, Kennedy WA, ShortliffeLM .Evaluation of sonographic renal parenchymal area in management of hydronephrosis .J Urol 2001; 165:548-51

11. Cost GA, Merguerian PA, Cheerasarn SP, Shortliffe LM. Sonographic renal parenchymal and pelvicalyceal areas ;new quatitative parameters for renal sonography follow up. J Uroll 1996:156;725-9

12. Kis E,Verebely T,Kovi R,Mattyus I. The role of ultrasound in the follow up of postoperative changes after pyeloplasty. Pediatr Radiol998:28;247-9

13. Imaji $R$, Dewan PA. Calyx to parenchyma ratio in pelvi-ureteric junction obstruction .BJU Int 2002;89;73-7 